\title{
TRATAMENTO DE EFLUENTES CONTENDO METAIS TÓXICOS POR BIOSSORÇÃO UTILIZANDO BIOMASSA DE MACRÓFITAS MORTAS EM COLUNA DE LEITO FIXO
}

\author{
E. L. SILVA ${ }^{1}$, H. C. C. SANTOS ${ }^{1}$, T. C. de A. CAMPOS $^{1}$ e R. F. F. da COSTA $^{1}$ \\ ${ }^{1}$ Centro Universitário do Leste de Minas Gerais, Departamento de Engenharia Química \\ E-mail para contato: thamara.cristina.campos@gmail.com
}

\begin{abstract}
RESUMO - As metodologias convencionais de tratamento de efluentes contendo metais tóxicos englobam processos físico-químicos, dos quais podem ser citados: precipitação química, recuperação eletrolítica, troca iônica, adsorção, dentre outros. O custo de projeto destas metodologias vem desencadeando a busca por processos alternativos mais viáveis que visam à mesma eficiência, dentre estes, pode-se citar a biossorção. No presente trabalho foi avaliado a capacidade de biossorção da macrófita da espécie Eichhornia azurea. Para análise da conformação do processo de biossorção com relação ao seu mecanismo foram realizadas configurações do sistema em coluna de leito fixo. Os percentuais de remoção, nos instantes iniciais, para o sistema de $\mathrm{Pb}^{2+}$ e $\mathrm{Cd}^{2+}$ foram de $84,6 \%$ e $67,2 \%$, respectivamente, indicando a eficiência de remoção dos íons metálicos presentes em solução por meio do sistema em coluna de leito fixo por E. azurea.
\end{abstract}

\section{INTRODUÇÃO}

A poluição de natureza inorgânica provocada pelo despejo de efluentes industriais contendo metais tóxicos se caracteriza pela presença de substâncias tóxicas, que acima de determinadas concentrações são capazes de denegrir a qualidade dos corpos hídricos e do solo. Dentre os metais com potencial carcinogênico, mutagênico ou teratogênico, presentes em efluentes de despejo industrial tem-se como exemplo o arsênio, o bário, o cádmio, o cromo, o chumbo e o mercúrio (BRAGA et al., 2005).

O tratamento convencional de efluentes contendo metais tóxicos se caracteriza por processos físico-químicos. Um dos métodos usuais mais utilizados é a combinação do processo de precipitação química, com posterior sedimentação e filtração; porém é observada uma baixa eficiência de remoção para grandes volumes de efluente com baixa concentração metálica e um alto custo de processo como um todo. Uma das alternativas em substituição a este método é a adsorção por biossorventes (SPINELLI et al., 2005).

A adsorção é um processo de transferência de massa entre uma fase fluida, denominada de adsorvato, e uma fase sólida, denominada adsorvente, e o que dita a troca de compostos no meio está associado à concentração entre as espécies presentes no efluente e as espécies presentes na superfície da matriz sólida. Em um leito fixo é disposta a matriz sólida por meio da qual se dará a passagem do efluente. A capacidade máxima de adsorção é atingida quando ocorre o equilíbrio e consequente saturação da matriz sólida (BORBA, 2006). 
Neste trabalho foi estudada a capacidade da biomassa morta da macrófita aquática Eichhornia azurea como biossorvente para a remoção dos íons metálicos $\mathrm{Pb}^{2+}$ e $\mathrm{Cd}^{2+}$ presentes em solução.

\section{MATERIAIS E MÉTODOS}

A macrófita Eichhornia azurea foi coletada na lagoa da Barra, situada no distrito de Baixa Verde do município de Dionísio - MG. Após ser seca em temperatura ambiente, a mesma foi triturada em liquidificador comum.

Foram utilizados soluções sintéticas para simular os efluentes industriais submetidos ao processo de tratamento, sendo as mesmas preparadas a partir dos sais nitrato de chumbo II $\mathrm{Pb}\left(\mathrm{NO}_{3}\right)_{2}$, e cloreto de cádmio hidratado, $\mathrm{CdCl}_{2}$ × 2,5 $\mathrm{H}_{2} \mathrm{O}$; optou-se por utilizar as concentrações variando de 30 a $170 \mathrm{mg} / \mathrm{L}$, conforme adaptação da metodologia utilizada por Silva, J. (2006). A escolha dos metais tóxicos se deu com base nas características dos efluentes das indústrias da região do Vale do Aço (BRASIL, 2014 apud FIEMG, 2016).

A partir da preparação dos referidos adsorvente e adsorvatos citados anteriormente foi realizado o teste em coluna de leito fixo. Nos ensaios de coluna de leito fixo foram preparados dois sistemas, um para biossorção de $\mathrm{Pb}^{2+}$ e outra para $\mathrm{Cd}^{2+}$. A montagem destes sistemas se deu em buretas de $100 \mathrm{~mL}$ da Vidrolabor ${ }^{\circledR}$ de dimensões conhecidas; para evitar a perda de biomassa na saída da coluna foi introduzida lã de vidro até o nível de volume $0 \mathrm{~mL}$. Foram compactados 4,007 e 4,004 g de biomassa, respectivamente, no sistema para $\mathrm{Pb}^{2+}$ e $\mathrm{Cd}^{2+}$, atingindo uma altura de $100 \mathrm{~mm}$ de leito fixo em ambas. As colunas foram alimentadas manualmente, em um fluxo descendente, com auxílio de uma proveta de $100 \mathrm{~mL}$. A vazão foi mantida constante e controlada pela válvula situada na parte inferior da bureta, de forma que a mesma fosse de $8,5 \mathrm{~cm}^{3} \cdot \mathrm{min}^{-1} \mathrm{em}$ ambas as colunas. Os efluentes tratados foram recolhidos em béqueres de $100 \mathrm{~mL}$ e a cada $100 \mathrm{~mL}$ tratados, para análise da concentração dos metais, até a saturação da biomassa.

A determinação da concentração das alíquotas dos efluentes tratados foram feitas por meio de titulação complexiométrica com o ácido etilenodiaminotetraacético (EDTA) e indicador negro de eriocromo T, utilizando ainda cerca de 2 gotas de $\mathrm{NaOH} 5 \%$, e $5 \mathrm{~mL}$ de solução tampão pH 10 para evitar alterações no pH da solução durante a titulação.

\section{RESULTADOS E DISCUSSÃO}

\subsection{Biossorção em coluna de leito fixo}

Para o estudo de biossorção, em regime contínuo, dos metais $\mathrm{Pb}^{2^{+}}$e $\mathrm{Cd}^{2+}$ em biomassa da macrófita $E$. azurea foram utilizados dois esquemas de coluna de biossorção em leito fixo de fluxo descendente.

A escolha de um leito fixo em vez de um reator em batelada tem como principal vantagem a combinação de uma ótima capacidade de biossorção, com adsorvato (efluente) à coluna com concentrações ainda mais baixas, uma vez que o biossorvente pode, efetivamente, reter os compostos que se deseja remover da solução que percola a coluna (GASPAR, 2003). 
Na Tabela 1 estão apresentados os parâmetros de dimensionamento da coluna, bem como caracterização física do leito biossorvente.

Tabela 1 - Dimensionamento da coluna de leito fixo e caracterização física do leito biossorvente

\begin{tabular}{lll}
\hline Coluna & $\mathbf{P b}^{2+}$ & $\mathbf{C d}^{2+}$ \\
\hline Biossorvente & Biomassa de E. azurea & Biomassa de E. azurea \\
Adsorvato & Efluente com $\mathrm{Pb}^{2+}$ & Efluente com Cd ${ }^{2+}$ \\
Concentração de entrada $-\mathrm{C}_{0}(\mathrm{ppm})$ & 166,90215 & 149,87728 \\
Diâmetro interno da coluna $-\phi(\mathrm{cm})$ & 1,60 & 1,60 \\
Massa do leito fixo $-\mathrm{m}_{\mathrm{s}}(\mathrm{g})$ & 4,007 & 4,004 \\
$\mathrm{~h}$ Leito fixo $(\mathrm{cm})$ & 10,00 & 10,00 \\
$\mathrm{~h}$ coluna $(\mathrm{cm})$ & 62,00 & 62,00 \\
$\mathrm{~h}$ coluna parte graduada $(\mathrm{cm})$ & 50,00 & 50,00 \\
Área $\left(\mathrm{cm}^{2}\right)$ & 311,646 & 311,646 \\
Volume total $\left(\mathrm{cm}^{3}\right)$ & 124,658 & 124,658 \\
Volume parte graduada $\left(\mathrm{cm}^{3}\right)$ & 100,531 & 100,531 \\
Fluxo volumétrico $-\mathrm{Fm}\left(\mathrm{cm}^{3} / \mathrm{min}\right)$ & 8,50 & 8,50 \\
Temperatura de operação $\left({ }^{\circ} \mathrm{C}\right)$ & 30,00 & 30,00 \\
\hline
\end{tabular}

Nos ensaios em coluna de leito fixo, a capacidade de biossorção dos metais $\mathrm{Pb}^{2+} \mathrm{e} \mathrm{Cd}^{2+}$ pela macrófita $E$. azurea foi avaliada pela retirada de alíquotas na saída da coluna após intervalos de $0,100 \mathrm{~L}$ dos efluentes sintéticos contendo metais de concentração inicial conhecida, de $166,90215 \mathrm{mg} / \mathrm{L}$ para o chumbo e $149,87728 \mathrm{mg} / \mathrm{L}$ para o cádmio, e quantificada pelo método titulométrico onde as análises foram realizadas em triplicata e utilizado o volume médio de titulação $(\mathrm{Tm})$, sendo as concentrações e o percentual de remoção calculados, respectivamente, pelas Equações 1 e 2. Os resultados obtidos se encontram na Tabela 2.

$$
\begin{aligned}
& C_{\text {metal }}=\frac{C_{E D T A} \times F c_{E D T A} \times V_{t}}{V_{a l_{t}}} \\
& R=\frac{C_{0}-C}{C_{0}} .100
\end{aligned}
$$

O equacionamento expresso na Equação 2, para a determinação da fração removida pelo biossorvente, foi realizado com base na metodologia proposta por Schneider (1995). 


\section{Congresso Brasileiro de Engenharia Química em Iniciação Científica UFSCar - São Carlos - SP 16 a 19 de Julho de 2017}

Tabela 2 - Resultados dos ensaios em coluna de leito fixo para $\mathrm{Pb}^{2+} \mathrm{e} \mathrm{Cd}^{2+}$

\begin{tabular}{|c|c|c|c|c|c|c|c|c|c|}
\hline \multicolumn{5}{|c|}{ Resultados para o $\mathbf{P b}^{2+}$} & \multicolumn{5}{|c|}{ Resultados para o $\mathbf{C d}^{2+}$} \\
\hline $\begin{array}{c}\text { Vol. } \\
\text { Adicionado } \\
\text { (L) }\end{array}$ & $\begin{array}{c}\text { Tm } \\
\text { com } \\
\text { EDTA } \\
\text { (L) }\end{array}$ & $\mathbf{C}$ & $\mathrm{C} / \mathrm{C}_{0}$ & $\begin{array}{c}\% \\
\text { Remoção }\end{array}$ & $\begin{array}{c}\text { Vol. } \\
\text { Adicionado } \\
\text { (L) }\end{array}$ & $\begin{array}{c}\text { Tm } \\
\text { com } \\
\text { EDTA } \\
(\mathbf{L})\end{array}$ & $\mathbf{C}$ & $\mathrm{C} / \mathrm{C}_{0}$ & $\begin{array}{c}\% \\
\text { Remoção }\end{array}$ \\
\hline 0 & 0,0058 & 166,90215 & 1,00000 & 0,0 & 0 & 0,0192 & 149,87728 & 1,00000 & 0,0 \\
\hline 0,1 & 0,0047 & 25,73967 & 0,15422 & 84,6 & 0,1 & 0,0048 & 37,72952 & 0,25174 & 67,2 \\
\hline 0,2 & 0,0100 & 54,94780 & 0,32922 & 67,1 & 0,2 & 0,0109 & 85,08658 & 0,56771 & 38,8 \\
\hline 0,3 & 0,0219 & 120,11844 & 0,71969 & 28,0 & 0,3 & 0,0157 & 122,29570 & 0,81597 & 16,5 \\
\hline 0,4 & 0,0058 & 166,90215 & 1,00000 & 0,0 & 0,4 & 0,0172 & 134,00486 & 0,89410 & 9,5 \\
\hline 0,5 & 0,0058 & 166,90215 & 1,00000 & 0,0 & 0,5 & 0,0184 & 143,37219 & 0,95660 & 3,9 \\
\hline 0,6 & 0,0058 & 166,90215 & 1,00000 & 0,0 & 0,6 & 0,0192 & 149,87728 & 1,00000 & 0,0 \\
\hline 0,7 & 0,0058 & 166,90215 & 1,00000 & 0,0 & 0,7 & 0,0192 & 149,87728 & 1,00000 & 0,0 \\
\hline
\end{tabular}

Os primeiros $100 \mathrm{~mL}$ biossorvidos são os que obtiveram os maiores valores de remoção; pois a solução de concentração de metal relativamente alta é colocada em contato inicial com o biossorvente novo e de alta capacidade de remoção (GASPAR, 2003), isso confirma a efetiva remoção dos metais em solução, no primeiro instante, onde se obteve $84,6 \%$ de remoção para o $\mathrm{Pb}^{2+}$ e $67,2 \%$ de remoção para o $\mathrm{Cd}^{2+}$. Até atingir o equilíbrio de biossorção, o biossorvente, é percolado por maior volume da solução, implicando em uma significativa diminuição gradual de sua capacidade de adsorção.

A biossorção em leito fixo possui grandes vantagens na aplicação em engenharia de processos, pois, é uma operação simples e de alto rendimento. Além disso, a coluna de leito fixo é um equipamento fácil de dimensionar, conforme visto no presente trabalho, basta a realização de alguns testes em escala laboratorial para então expandir a nível industrial (GASPAR, 2003).

\section{CONCLUSÃO}

Por meio dos resultados obtidos pode-se comprovar a capacidade de biossorção da macrófita aquática Eichhornia azurea, além da viabilidade econômica do processo, visto que esta planta é considerada daninha. 
Com relação aos ensaios de biossorção em coluna de leito fixo houve resultado satisfatório na remoção de ambos os metais. Os resultados obtidos permitem afirmar que, por meio do aumento do leito fixo da coluna, ou até mesmo com o emprego de outras colunas interligadas em série é possível obter um aumento considerável na capacidade de remoção da coluna, de modo com que o efluente, ao final do processo, esteja dentro dos limites de emissão estabelecidos pela legislação.

\section{LISTA DE ABREVIATURAS E SIGLAS}

\begin{tabular}{|c|c|}
\hline $\mathrm{C}$ & Concentração (mg/L) \\
\hline $\mathrm{C}_{0}$ & Concentração inicial de adsorvato na solução (mg/L) \\
\hline $\mathrm{C}_{\mathrm{EDTA}}$ & Concentração da solução de EDTA utilizada na titulação (mol/L) \\
\hline $\mathrm{C}_{\text {metal }}$ & Concentração do metal presente em solução (mol/L) \\
\hline $\mathrm{Cd}^{2+}$ & Íon cádmio II \\
\hline $\mathrm{CdCl}_{2} \times 2,5 \mathrm{H}_{2} \mathrm{O}$ & Cloreto de cádmio hidratado \\
\hline $\mathrm{cm}$ & Centímetros \\
\hline $\mathrm{cm}^{2}$ & Centímetros quadrados \\
\hline $\mathrm{cm}^{3}$ & Centímetros cúbicos \\
\hline E. azurea & Eichhornia azurea \\
\hline $\mathrm{Fc}_{\mathrm{EDTA}}$ & Fator de correção da solução de EDTA \\
\hline FIEMG & Federação das Indústrias do Estado de Minas Gerais \\
\hline Fm & Vazão de escoamento \\
\hline g & Grama \\
\hline $\mathrm{L}$ & Litro \\
\hline M & Molar (mol/L) \\
\hline $\mathrm{mg}$ & Miligrama \\
\hline MG & Minas Gerais \\
\hline $\min$ & Minuto \\
\hline $\mathrm{mm}$ & Milímetros \\
\hline $\mathrm{mL}$ & Mililitros \\
\hline $\mathrm{NaOH}$ & Hidróxido de sódio \\
\hline $\mathrm{Pb}^{2+}$ & Íon chumbo II \\
\hline $\mathrm{Pb}\left(\mathrm{NO}_{3}\right)_{2}$ & Nitrato de chumbo II \\
\hline $\mathrm{pH}$ & Potencial hidrogeniônico \\
\hline
\end{tabular}




$\begin{array}{ll}\text { ppm } & \text { Partes por milhão } \\ \mathrm{R} & \text { Percentual de remoção do adsorvato pelo biossorvente } \\ \mathrm{Tm} & \text { Volume médio de titulação (L) } \\ \mathrm{V} & \text { Volume (L) } \\ \mathrm{V}_{\mathrm{al}} & \text { Volume da alíquota da solução de metal presente no erlenmeyer } \\ & \text { para a titulação (L) } \\ \mathrm{V}_{\mathrm{t}} & \text { Volume de EDTA gasto na titulação (L) }\end{array}$

\section{REFERÊNCIAS}

BORBA, Carlos Eduardo. Modelagem da remoção de metais pesados em coluna de adsorção de leito fixo. 2006. 168 f. Dissertação (Mestrado em Engenharia Química)Universidade Estadual de Campinas, Campinas, 2006.

BRAGA, Benedito; HESPANHOL, Ivanildo; CONEJO, João G. Lotufo; MIERZWA, José Carlos; BARROS, Mario Thadeu L. de; SPENCER, Milton; PORTO, Monica; NUCCI, Nelson; JULIANO, Neusa; EIGER, Sérgio. Introdução à Engenharia Ambiental- O desafio do desenvolvimento sustentável. 2 ed. São Paulo: Pearson Prentice Hall, 2005. $318 \mathrm{p}$.

FIEMG. Conheça os setores dinamizadores da região. Disponível em: <http://pcir.fiemg.com.br/regionais/detalhe/vale-do-aco>. Acesso em: 10 jun. 2016.

GASPAR, A.T.F.S. Biossorção de cromo em algas marinhas utilizando coluna extratora. 2003. Dissertação (Mestrado em Engenharia Química) - Universidade Estadual de Campinas, Campinas, 2003.

SILVA, Jean Ferreira. Análise experimental e simulação do processo de bioadsorção de metais pesados (Pb, Zn e Ni) através da alga marinha Sargassum sp. 2006. 179 f. Tese (Doutorado em Engenharia Química) - Universidade Estadual de Campinas, Campinas, 2006.

SCHNEIDER, Ivo André Homrich. Biossorção de metais pesados com a biomassa de macrófitos aquáticos. 1995. 157 f. Tese (Doutorado em Engenharia Metalúrgica Extrativa)-Universidade Federal do Rio Grande do Sul, Porto Alegre, 1995.

SPINELLI, Viviane A.; LARANJEIRA, Mauro C. M.; FÁVERE, Valfredo T.; KIMURA, Irene Y.. Cinética e Equilíbrio de Adsorção dos Oxiânions Cr (VI), Mo (VI) e Se (VI) pelo Sal de Amônio Quaternário de Quitosana. Polímeros: Ciência e Tecnologia, vol. $15, \mathrm{n}^{\mathrm{o}} 3, \mathrm{p} .218-223,2005$. 